\title{
Added catalyst-free, versatile and environment beneficial bromination of (hetero)aromatics using NBS in WEPA
}

\author{
Rama Moorthy Appa ${ }^{1}$. Bandameeda Ramesh Naidu ${ }^{1}$. Jangam Lakshmidevi ${ }^{1}$ Jyothi Vantikommu . \\ Katta Venkateswarlu' ${ }^{1}$
}

(c) Springer Nature Switzerland AG 2019

\begin{abstract}
The aromatic or heteroaromatic bromides are the quite common substrates in several organic transformations. The synthesis of arylbromides is challenging and required expensive catalytic systems or problematic organic solvents. This article unveils an environment beneficial, versatile and facile procedure for the synthesis of aryl/heteroaryl bromides using $\mathrm{N}$-bromosuccinimide in water extract of pomegranate ash. The preparation of bromoarenes or bromoheteroarenes was accomplished under atmospheric conditions in the absence of added catalyst, promoter, problematic solvent and additives. The products were formed with greater rates in very high to quantitative yields using biowaste derived media shows the environmental benefits like utilization of waste, safer media, rich chemical economy, economic feasibility and dwindling the chemical waste, has eventual scope towards further explorations.
\end{abstract}

\section{Graphic abstract}

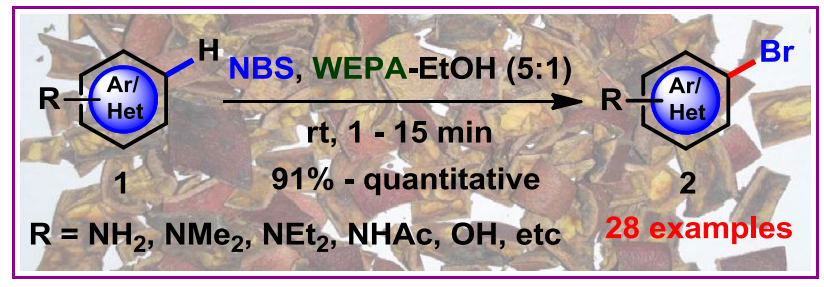

Keywords Water extract of pomegranate ash - N-Bromosuccinimide - Sustainable media - Nuclear bromination . Bromo(hetero)arenes · Economical process

\section{Introduction}

The nuclear bromination of aromatic or heteroaromatic compounds is the frequently used transformation in making highly reactive aryl/heteroaryl bromides. These bromides are the principal substrates in the synthesis of biaryls, aryl amines, organometallics, cinnamate esters, functional materials and diverse biologically effective organics [1-7]. By virtue of this essentiality a sizeable efforts have been appeared in the literature for the preparation of aryl bromides and heteroaryl bromides. In this context, Das et al. [8-10] explored NBS/

Electronic supplementary material The online version of this article (https://doi.org/10.1007/s42452-019-1274-x) contains supplementary material, which is available to authorized users.

Katta Venkateswarlu, kvenkat@yogivemanauniversity.ac.in; venkatkatta84@gmail.com | 'Laboratory for Synthetic \& Natural Products Chemistry, Department of Chemistry, Yogi Vemana University, Kadapa 516005, India. ${ }^{2}$ Centre for Chemical Science and Technology, Institute of Science and Technology, Jawaharlal Nehru Technological University Hyderabad, Hyderabad 500 085, India. 
sulfonic-acid-functionalized silica, $\mathrm{NBS} / \mathrm{NH}_{4} \mathrm{OAc}$ and NBS/PEG-400 systems for the nuclear brominations. Further, $\mathrm{NH}_{4} \mathrm{Br}$ /oxone [11], $\mathrm{CuBr}_{2}$ /oxone [12], $\mathrm{HBr} / \mathrm{H}_{2} \mathrm{O}_{2}$ / $\mathrm{AcOH}$ [13], $\mathrm{CaBr}_{2} / \mathrm{Br}_{2}$ [14], NBS/pTSA [15], $\mathrm{Br}_{2}$ /lithium tetramethylpiperidide (LiTMP) [16], $\mathrm{NH}_{4} \mathrm{Br} / \mathrm{H}_{2} \mathrm{O}_{2} / \mathrm{AcOH}$ [17] and $\mathrm{Br}_{2} / \mathrm{LDH}-\mathrm{WO}_{4} / \mathrm{H}_{2} \mathrm{O}_{2}$ [18] are the significant methods for this purpose. However, majority of these procedures require added catalysts, oxidants, nonconventional solvents, reagents or large reaction times were occasionally operated at harsh conditions. Most recently, NBS/PhSSPh (or PhSSiMe 3 ) [19], NBS/indoles [20], NBS/hexafluoroisopropanol [21], NBS/ $\mathrm{I}_{2}$ [22], $\mathrm{NaBr} /$ $\mathrm{H}_{2} \mathrm{O}_{2} / \mathrm{ACOH}$ [23] and 1,2-ethanediylbis(triphenylphosph onium)-ditribromide [24] were found attractive. Nevertheless, these also suffer with the necessity of catalysts, expensive solvents, oxidants or large reaction times. Therefore, it is extremely desirable to establish the operationally simple, cost-effective and substantially benign protocols for the synthesis of aryl/heteroaryl bromides.

NBS is the best reagent among all the conventional reagents that are employed for nuclear brominations, because, it makes easy the electrophilic substitutions under mild conditions, readily available, inexpensive and ease of handling [25]. Moreover, NBS has been explored as catalyst in several prevalent organic transformations [25].

Recently the agro-waste extracts (AWEs) are found as alternative and renewable media for the several significant organic reactions offers tremendous environmental benefits like sustainability, safeness, ease of preparation and choice of avoiding the volatile organic solvents, bases, ligands, and so on [5, 6, 26-29]. In this context, the ligand and (or) added base free Suzuki-Miyaura [6, 28], Sonogashira [28], Henry [2, 28], Ullmann [5] and Michael [30] reactions were developed in which the use of the AWEs found crucial. Further, the efficient protocols for the synthesis of 3-carboxycoumarins [31], bisenols [32], disulfides [29], phenols (from arylboronic acids) [26] and allylthioethers [33] were also appeared using AWEs, which act as sole catalysts as well as media. Furthermore, green chemistry reveals that the use of aqueous (or non toxic) media is the superior technique in decreasing the ecological pollution [34]. In pharmaceutical industry the organic solvents cover $\sim 85 \%$ of the chemicals that are used can be recycled hardly at $50-80 \%$ rate [35] which generates enormous amount of environmental waste.

The economic and environmental impacts of the AWEs prompted us to investigate on these media in developing new synthetic methodologies. Thus, in continuation of our recent investigations on WEPA $[5,6,36]$, we report here a green protocol for the bromination of arenes or heteroarenes using NBS in WEPA at room temperature (rt) under added catalyst and volatile solvent free aerobic conditions.
This protocol implies the future scope of bio-waste derived extract, WEPA in organic synthesis.

\section{Experimental}

\subsection{General information}

The aromatic and heteroaromatic compounds, NBS, solvents and other materials used in the present investigation were procured from Merck, Spectrochem, Sigma-Aldrich and Alfa-Aesar. The reaction progress was ensured by thin layer chromatography (TLC). The NBS was recrystallized in water prior to its use. Silica gel (60-120 mesh-Merck) packed glass columns were employed for the separation of brominated products using a mixture of EtOAc and hexanes. ${ }^{13} \mathrm{C} \&$ (or) ${ }^{1} \mathrm{H}$ NMR spectra were recorded using Brucker Avance 100/400 MHz spectrometer using tetramethylsilane (TMS) as an internal standard. Coupling constant $(J)$ was represented in $\mathrm{Hz}$ and the chemical shifts $(\delta)$ in ppm with the signal pattern: $s$, singlet; $m=$ multiplet; $d$, doublet; $\mathrm{t}$, triplet; $\mathrm{q}=$ quartet; $\mathrm{dd}$, doublet of doublet; and brs, broad singlet.

\subsection{Experimental procedures}

Preparation of WEPA $[5,6,36]$ The small pieces of fairly dried pomegranate peels were burned to ash. $10 \mathrm{~g}$ of ash was suspended in $100 \mathrm{~mL}$ of distilled water. The resultant suspension was subjected for stirring at $80^{\circ} \mathrm{C}$ for $1 \mathrm{~h}$. Finally pale yellow extract (WEPA) was obtained by cooling and filtering the resultant mixture.

General experimental procedure Dissolved aryl or heteroaryl compound (1) $(1 \mathrm{mmol})$ in a $3 \mathrm{~mL}$ mixture of WEPA and EtOH (5:1). $1.02 \mathrm{mmol}$ of recrystallized NBS was then added and allowed the resultant mixture for stirring at rt. The bromination process was ensured by thin layer chromatography and after bromination (Table 2) the EtOH was evaporated in vacuo. Added $10 \mathrm{~mL}$ of EtOAc and $10 \mathrm{~mL}$ of distilled water to the resultant mixture, transferred to a separatory funnel and separated the organic (EtOAc) portion. Further extraction of aqueous layer was performed with EtOAc $(2 \times 7 \mathrm{~mL})$ and all the EtOAc extracts were combined. Dried the combined EtOAc portions using anhydrous $\mathrm{MgSO}_{4}$ and purified the products using column chromatography. The structures of all the aryl/heteroaryl bromides (2) were ascertained from their ${ }^{13} \mathrm{C}$ NMR \& (or) ${ }^{1} \mathrm{H}$ NMR and mass spectral data and these resembles the reported data. The characterization data and copies of ${ }^{1} \mathrm{H}$ $\&^{13} \mathrm{C}$ NMR spectra of the products were provided at online supporting information. 


\section{Results and discussion}

In the initial screening towards the optimization of the reaction conditions, we used to react 4-methylphenol (1 aa) $(1 \mathrm{mmol}$ ) with $0.5 \mathrm{mmol}$ of NBS in $1.5 \mathrm{~mL}$ of WEPA at $\mathrm{rt}$ and observed the formation of 2-bromo-4-methylphenol (2aa) in $18 \%$ yield in 15 min (Table 1, entry 1 ). Further increase of media, (WEPA) to $2.0,2.5$ and $3.0 \mathrm{~mL}$, formed the product, $\mathbf{2}$ aa in $25 \%, 39 \%$ and $39 \%$ yields in $15 \mathrm{~min}$ (Table 1, entries 2-4) indicates the requirement $2.5 \mathrm{~mL}$ of WEPA for this bromination. The addition of $0.5 \mathrm{~mL}$ of ethanol at this stage enhanced the yield of 2 aa to $48 \%$ in just 5 min (Table 1, entry 5). However the formation of $<2 \%$ of 2 aa along with $4 \%$ of 2,6 -dibromo4-methylphenol (3) was observed using ethanol as sole solvent (Table 1, entry 6) indicates ethanol helps only to dissolve the substances. The formation of quantitative yield of 2aa was observed when the amount of NBS was enhanced to $1.02 \mathrm{mmol}$ using a mixture of $2.5 \mathrm{~mL}$ of WEPA and $0.5 \mathrm{~mL}$ of ethanol (Table 1, entry 7). The reaction was then conducted at $0{ }^{\circ} \mathrm{C}, 50^{\circ} \mathrm{C}$ and $80^{\circ} \mathrm{C}$ using $1 \mathrm{mmol}$ of $1 \mathrm{aa}, 1.02 \mathrm{mmol}$ of NBS, $2.5 \mathrm{~mL}$ of WEPA and $0.5 \mathrm{~mL}$ of ethanol, and identified the formation of quantitative yield of $\mathbf{2 a a}$ (Table 1, entries 8-10) indicates these conditions are not showed any influence on the WEPA catalyzed bromination of $1 \mathbf{a a}$. We also investigated the influence of the excess amount of NBS on the current reaction. In this connection we used $1.5 \mathrm{mmol}$ and $2.02 \mathrm{mmol}$ of NBS and found the formation of 2,6-dibromo-4-methylphenol (3) in 47\% and $97 \%$ along with $51 \%$ and $0 \%$ of $\mathbf{2 a a}$ (Table 1, entries 11 \& 12), which indicates the requirement of $1.02 \mathrm{mmol}$ of NBS for the selective monobromination of aromatic systems under the present experimental conditions. The optimized conditions were then exercised on a variety of aromatics or heteroaromatics and the results are listed in Table 2.

Phenols and anilines with electron-donating methyl, bromo, iodo and phenyl groups were made easily into their monoiodo derivatives with high regioselectivity in 1-5 min with $96 \%$ to quantitative yields (Table 2 , entries 2-8). Unsubstituted phenol (1 ai) and aniline (1 $\mathbf{a j}$ ) were also found to be very quick in brominations under WEPA catalysis to give $91 \%$ and $93 \%$ yields of 4-bromophenol (2ah) and 4-bromoaniline (2ai) (Table 2, entries $9 \& 10)$, however, minor amounts of positional isomers were observed in these two cases. N,N-Dimethyl (1 $\mathbf{a k}$ ), $\mathrm{N}, \mathrm{N}$-diethyl (1 al) and $\mathrm{N}$-acetyl (1 am) anilines forms only para brominated products $\mathbf{2} \mathbf{a j}-\mathbf{2} \mathbf{a l}$ in $\mathbf{1 - 1 0} \mathrm{min}$ (Table 2, entries 11-13). 2-Naphthol (1 an), 2-naphthylamine (1 ao) and 1-naphthylamine (1 ap) gave the monobrominated products (2am-2ao) in 2 min with 92-quantitative yields (Table 2, entries 14-16) and minor amount of regio isomer was found with 1 ap.

Table 1 Optimization of reaction conditions

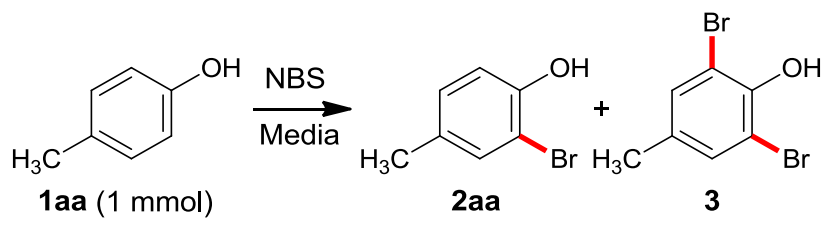

\begin{tabular}{|c|c|c|c|c|c|}
\hline Entry & NBS (mmol) & Medium (mL) & Temperature $\left({ }^{\circ} \mathrm{C}\right)$ & Time (min) & Isolated yield 1aa:3 (\%) \\
\hline 1 & 0.50 & WEPA (1.5) & Rt & 15 & $18: 0$ \\
\hline 2 & 0.50 & WEPA (2.0) & Rt & 15 & $25: 0$ \\
\hline 3 & 0.50 & WEPA (2.5) & Rt & 15 & $39: 0$ \\
\hline 4 & 0.50 & WEPA (3.0) & Rt & 15 & $39: 0$ \\
\hline 5 & 0.50 & WEPA (2.5) + EtOH (0.5) & Rt & 5 & $48: 0$ \\
\hline 6 & 0.50 & $\mathrm{EtOH}(3.0)$ & Rt & 60 & $<2: 4$ \\
\hline 7 & 1.02 & WEPA (2.5) + EtOH (0.5) & Rt & 1 & Quantitative:0 \\
\hline 8 & 1.02 & WEPA (2.5) + EtOH (0.5) & 0 & 5 & Quantitative:0 \\
\hline 9 & 1.02 & WEPA (2.5) + EtOH (0.5) & 50 & 1 & Quantitative:0 \\
\hline 10 & 1.02 & WEPA (2.5) + EtOH (0.5) & 80 & 1 & Quantitative:0 \\
\hline 11 & 1.50 & WEPA (2.5) + EtOH (0.5) & Rt & 1 & $51: 47$ \\
\hline 12 & 2.02 & WEPA (2.5) + EtOH (0.5) & Rt & 1 & $0: 97$ \\
\hline
\end{tabular}


Table 2 Bromination of (hetero)aromatics using NBS in WEPA
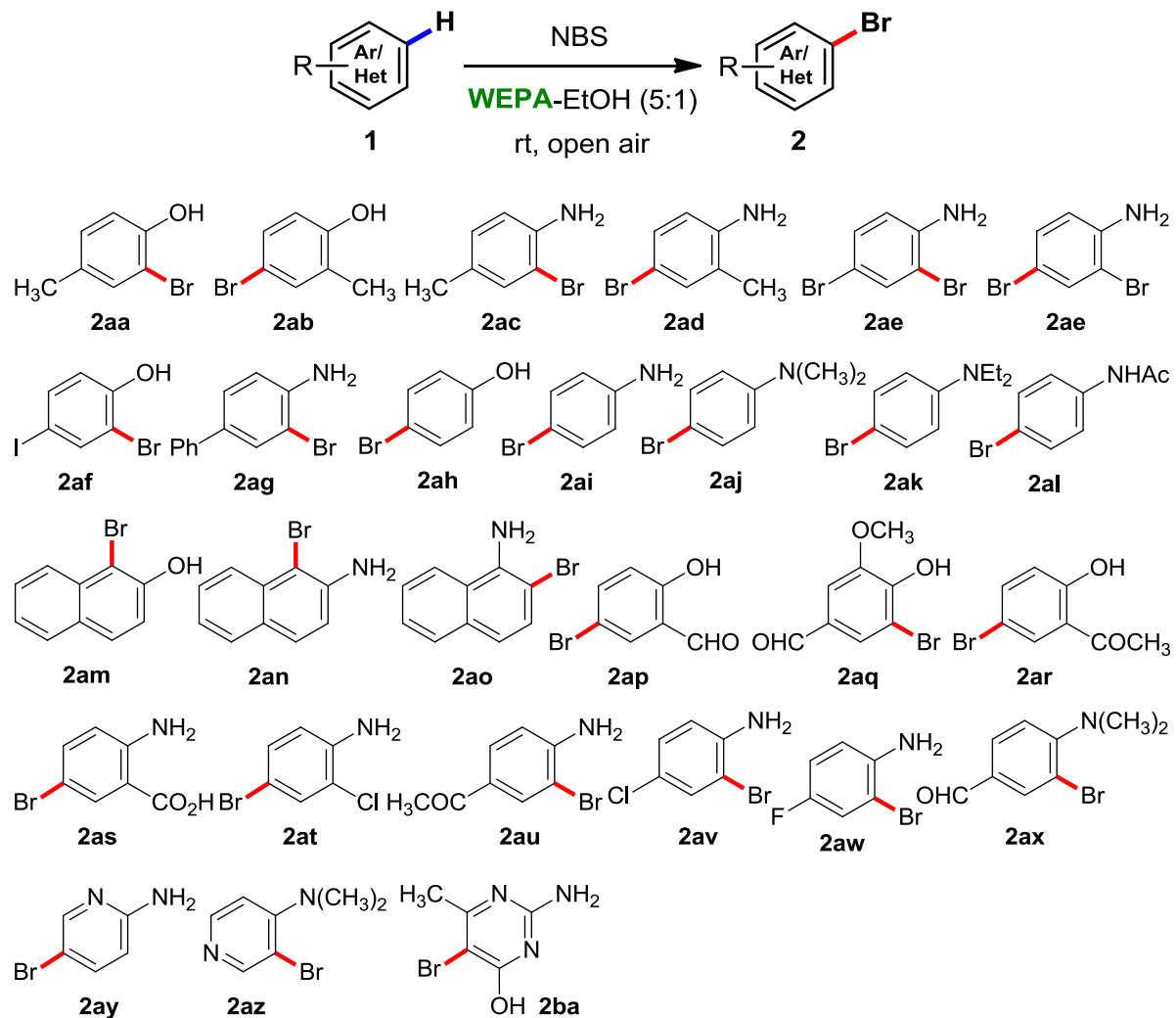

\begin{tabular}{|c|c|c|c|c|}
\hline Entry & Substrate (1) & Time $(\min )$ & Product (2) & Isolated yield (\%) \\
\hline 1 & 4-Methylphenol (1 aa) & 1 & $2 a a$ & Quantitative \\
\hline 2 & 2-Methylphenol (1 $\mathbf{a b})$ & 1 & $2 a b$ & 97 \\
\hline 3 & 4-Methylaniline (1ac) & 1 & $2 a c$ & Quantitative \\
\hline 4 & 2-Methylaniline (1 ad) & 1 & $2 \mathrm{ad}$ & 98 \\
\hline 5 & 4-Bromoaniline (1 ae) & 1 & $2 a e$ & 97 \\
\hline 6 & 2-Bromoaniline (1 af) & 1 & $2 a e$ & Quantitative \\
\hline 7 & 4-lodophenol (1 ag) & 1 & 2af & Quantitative \\
\hline 8 & 4-Aminobiphenyl (1 ah) & 5 & $2 a g$ & 96 \\
\hline 9 & Phenol (1 ai) & 1 & $2 a h$ & 91 \\
\hline 10 & Aniline (1aj) & 1 & 2ai & 93 \\
\hline 11 & $N, N$-Dimethylaniline (1 ak) & 1 & 2aj & Quantitative \\
\hline 12 & $N, N$-Diethylaniline (1 $\mathbf{a l})$ & 1 & 2ak & Quantitative \\
\hline 13 & Acetanilide (1 am) & 10 & 2al & 92 \\
\hline 14 & 2-Naphthol (1an) & 2 & 2am & Quantitative \\
\hline 15 & 2-Naphthylamine (1 ao) & 2 & $2 a n$ & Quantitative \\
\hline 16 & 1-Naphthylamine (1 ap) & 2 & $2 a o$ & 92 \\
\hline 17 & Salicylaldehyde (1aq) & 15 & 2ap & 95 \\
\hline 18 & Vanillin (1 ar) & 5 & $2 a q$ & 97 \\
\hline 19 & 2-Hydroxyacetophenone (1 as) & 15 & $2 a r$ & 92 \\
\hline 20 & 2-Aminobenzoic acid (1 at) & 15 & 2as & 93 \\
\hline 21 & 2-Chloroaniline (1 $\mathbf{a u})$ & 10 & 2at & 98 \\
\hline 22 & 4-Aminoacetophenone (1 av) & 15 & 2au & 95 \\
\hline 23 & 4-Chloroaniline (1 aw) & 15 & $2 a v$ & 96 \\
\hline
\end{tabular}


Table 2 (continued)

\begin{tabular}{llrll}
\hline Entry & Substrate (1) & Time (min) & Product (2) & Isolated yield (\%) \\
\hline 24 & 4-Fluoroaniline (1ax) & 5 & 2aw & 96 \\
25 & 4-N,N-Dimethylbenzaldehyde (1 ay) & 15 & $\mathbf{2 a x}$ & 97 \\
26 & 2-Aminopyridine (1 az) & 1 & $\mathbf{2 a y}$ & 96 \\
27 & 4-N,N-Dimethylaminopyridine (1 ba) & 1 & $\mathbf{2 a z}$ & Quantitative \\
28 & 2-Amino-4-hydroxy-6-methylpyrimidine (1 $\mathbf{b b})$ & 10 & $\mathbf{2 b a}$ & 93 \\
\hline
\end{tabular}

Reaction conditions 1 (1 mmol), NBS (1.02 mmol), WEPA $(2.5 \mathrm{~mL})$ and EtOH $(0.5 \mathrm{~mL})$ at rt in open air

Phenols with electron-withdrawing, formyl and acetyl groups (1 aq-1as) and anilines with carboxyl, chloro, acetyl and fluoro groups (1at-1aw) formed excellent yields (92-97\%) of monobrominated products (2ap-2aw) with high regioselectivity in 5-15 min (Table 2, entries 17-24). 4-N,N-Dimethylbenzaldehyde (1 ay) was also produced $97 \%$ of 3-bromo-4- $N, N$-dimethylbenzaldehyde (2ax) in 15 min (Table 2, entry 25).

The heterocyclic arenes such as 2-aminopyridine (1 bz), 4-N,N-dimethylaminopyridine (1 ba) and 2-amino4-hydroxy-6-methylpyrimidine (1 $\mathbf{b b}$ ) were also observed as good substrates to form $93 \%$ to quantitative yields in 1-10 min under WEPA catalytic mediations (Table 2, entries 26-28).

A high chemoselectivity i.e., the selectivity of aromatic groups over a-position of a-methyl carbonyls ( $\mathbf{1}$ am, $\mathbf{1}$ as \& $\mathbf{1 a v}$ ) and benzylic methyl groups (1 $\mathbf{a a}-\mathbf{1}$ ad) was observed under the current development. Further, the high regioselectivity (i.e., the selectivity over the possible reactive cites) was the noteworthy future of this protocol. Moreover, the base sensitive amide (1 $\mathbf{a m})$ and methyl keto (1 as \& $\mathbf{1} \mathbf{a v}$ ) groups were also observed to be unaffected using these experimental conditions is an added advantage.

The process of WEPA accelerated bromination of aromatics/heteroaromatics is not fully understood at this point, but, it may be related to the electrophilic brominative cyclization of alkynoic acids in the presence of NBS and $\mathrm{K}_{2} \mathrm{CO}_{3}$ [37]. The species, $\mathrm{M}^{+} \mathrm{B}^{-}$of WEPA generates the electrophilic bromine intermediate, $\mathrm{Br}^{+} \mathrm{B}^{-}$which involves in substitution of heteroaromatic/aromatic systems (1) to give heteroaryl/aryl bromides (2) (Scheme 1). Further activation of aromatics/heteroaromatics is also possible in basic media WEPA by the polarization of heteroatom(oxygen or nitrogen)-hydrogen bonds. The high reactivity of aromatics/heteroaromatics towards bromination in WEPA leads further scope of investigations.
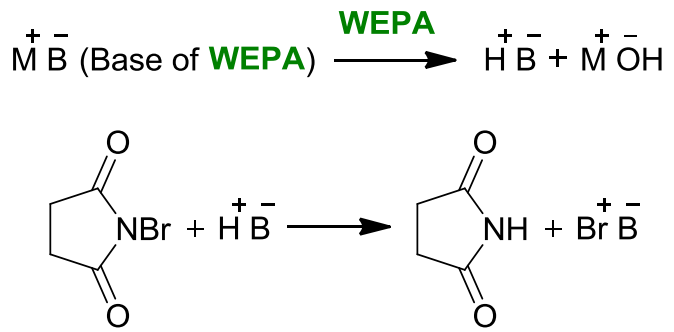

NBS

Succinimide

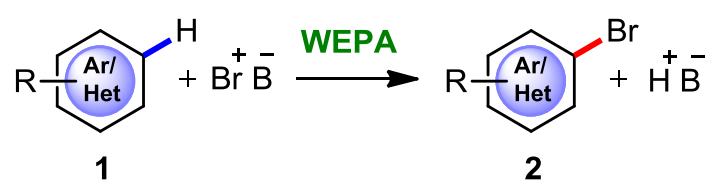

Scheme 1 Plausible pathway of bromination in NBS/WEPA system

\section{Conclusions}

In summary, a versatile, novel and highly economical protocol has been put forward for the monobromination of aromatics/heteroaromatics using WEPA as a catalytic media. The reactions can be implemented at ambient aerobic conditions using biowaste derived WEPA. The functional groups including hydroxy, amino, benzylicmethyl, formyl, methyl keto, carboxyl, amide and $\mathrm{N}, \mathrm{N}$ dialkyl got tolerated under WEPA promoted brominations of aromatics and heteroaromatics. A very high to quantitative yields of brominated products, utilization of agro-waste extract as catalytic media, actual usage of renewable resources, rich position, monobromination and chemoselectivity, high scope of reactants and easy operation of the reactions are the outstanding features of this finding. These findings open further scope of high-quality research using agro-waste derived catalytic media. 
Acknowledgements Authors are grateful to SERB, New Delhi for the financial support (No. SB/FT/CS-009/2014). JL thanks DST, New Delhi for INSPIRE fellowship (No. IF150772) and BRN thanks CSIR, New Delhi for JRF (No. 09/1076(0003)/2018-EMR-I).

\section{Compliance with ethical standards}

Conflict of interest The authors declare that they have no conflict of interests.

\section{References}

1. Dagani MJ, Barda HJ, Benya TJ, Sanders DC (2002) Ullmann's encyclopedia of industrial chemistry: bromine compounds. Wiley-VCH, Weinheim

2. Ruiz-Castillo P, Buchwald SL (2016) Application of palladiumcatalyzed C-N cross-coupling reactions. Chem Rev 116:1256412649. https://doi.org/10.1021/acs.chemrev.6b00512

3. Rao KU, Appa RM, Lakshmidevi J, Vijitha R, Rao KSVK, Narasimhulu $M$, Venkateswarlu K (2017) C $\left(\mathrm{sp}^{2}\right)-C\left(\mathrm{sp}^{2}\right)$ coupling in water: palladium(II) complexes of $\mathrm{N}$-pincer tetradentate porphyrins as effective catalysts. Asian J Org Chem 6:751-757. https://doi. org/10.1002/ajoc.201700068

4. Rao KU, Lakshmidevi J, Appa RM, Prasad SS, Narasimhulu M, Vijitha R, Rao KSVK, Venkateswarlu K (2017) Palladium(II)-porphyrin complexes as efficient and eco-friendly catalysts for Mizoroki-Heck coupling. ChemistrySelect 2:7394-7398. https ://doi.org/10.1002/slct.201701413

5. Lakshmidevi J, Appa RM, Naidu BR, Prasad SS, Sarma LS, Venkateswarlu K (2018) WEPA: a bio-derived medium for added base, $\pi$-acid and ligand free Ullmann coupling of aryl halides using $\mathrm{Pd}(\mathrm{OAc})_{2}$. Chem Commun 54:12333-12336. https://doi. org/10.1039/c8cc06940a

6. Appa RM, Prasad SS, Lakshmidevi J, Naidu BR, Narasimhulu M, Venkateswarlu K (2019) Palladium-catalysed room-temperature Suzuki-Miyaura coupling in water extract of pomegranate ash, a bio-derived sustainable and renewable medium. Appl Organomet Chem e5126:1-10. https://doi.org/10.1002/aoc.5126

7. Rao KU, Venkateswarlu K (2018) Pd"-porphyrin complexes-the first use as safer an efficient catalysts for Miyaura borylation. Synlett 29:1055-1060. https://doi.org/10.1055/s-0036-1591549

8. Das B, Venkateswarlu K, Krishnaiah M, Holla H (2006) An efficient, rapid and regioselective nuclear bromination of aromatics and heteroaromatics with NBS using sulfonic-acid-functionalized silica as a heterogeneous recyclable catalyst. Tetrahderon Lett 47:8693-8697. https://doi.org/10.1016/j.tetlet.2006.10.029

9. Das B, Venkateswarlu K, Majhi A, Siddaiah V, Reddy KR (2007) A facile nuclear bromination of phenols and anilines using NBS in the presence of ammonium acetate as a catalyst. J Mol Catal A Chem 267:30-33. https://doi.org/10.1016/j.molcata.2006.11.002

10. Venkateswarlu K, Suneel K, Das B, Reddy KN, Reddy TS (2009) Simple catalyst-free regio-and chemoselective monobromincation of aromatics using NBS in polyethylene glycol. Synth Commun 39:215-219. https://doi.org/10.1080/00397910801911752

11. Naresh M, Kumar MA, Reddy MM, Swamy P, Nanubolu JB, Narender N (2013) Fast and efficient bromination of aromatic compounds with ammonium bromide and oxone. Synthesis 45:1497-1504. https://doi.org/10.1055/s-0033-1338431

12. Li X-L, Wu W, Fan X-H, Yang L-M (2013) A facile, regioselective and controllable bromination of aromatic amines using a CuBr 2/oxone ${ }^{\circledR}$ system. RSC Adv 3:12091-12095. https://doi. org/10.1039/c3ra41664j
13. Koini EN, Avlonitis N, Calogeropoulou T (2011) Simple and efficient method for the halogenation of oxygenated aromatic compounds. Synlett 11:1537-1542. https://doi. org/10.1055/s-0030-1260792

14. Kumar L, Mahajan T, Agarwal DD (2011) An instant and facile bromination of industrially-important aromatic compounds in water using recyclable $\mathrm{CaBr}_{2}-\mathrm{Br}_{2}$ system. Green Chem 13:21872196. https://doi.org/10.1039/c1gc15359e

15. Bovonsombat $P$, Khanthapura $P$, Krause $M M$, Leykajarakul J (2008) Facile synthesis of 3-halo and mixed 3,5-dihalo analogues of $\mathrm{N}$-acety-L-tyrosine via sulfonic acid-catalysed regioselective monohalogenation. Tetrahedron Lett 49:7008-7011. https://doi. org/10.1016/j.tetlet.2008.09.123

16. Menzel K, Fisher EL, DiMichele L, Frantz DE, Nelson TD, Kress $\mathrm{MH}$ (2006) An improved method for the bromination of metalated haloarenes via lithium, zinc transmetalation: a convenient synthesis of 1,2-dibromoarenes. J Org Chem 71:21882191. https://doi.org/10.1021/jo052515k

17. Mohan KVVK, Narender N, Srinivasu P, Kulkarni SJ, Raghavan KV (2004) Novel bromination method for anilines and anisoles using $\mathrm{NH}_{4} \mathrm{Br} / \mathrm{H}_{2} \mathrm{O}_{2}$ in $\mathrm{CH}_{3} \mathrm{COOH}$. Synth Commun 34:21432152. https://doi.org/10.1081/SCC-120038491

18. Choudary BM, Someshwar T, Reddy ChV, Kantam ML, Ratnam KJ, Sivaji LV (2003) The first example of bromination of aromatic compounds with unprecedented atom economy using molecular bromine. Appl Catal A Gen 251:397-409. https:// doi.org/10.1016/S0926-860X(03)00379-X

19. Hirose Y, Yamazaki M, Nogata M, Nakamura A, Maegawa T (2019) Aromatic halogenation using $N$-halosuccinimide and $\mathrm{PhSSiMe}_{3}$ or PhSSPh. J Org Chem 84:7405-7410. https://doi. org/10.1021/acs.joc.9b00817

20. Shi Y, Ke Z, Yeung Y-Y (2018) Environmentally benign indolecatalyzed position-selective halogenation of thioarenes and other aromatics. Green Chem 20:4448-4452. https://doi. org/10.1039/c8gc02415d

21. Tang R-J, Milcent T, Crousse B (2018) Regioselective halogenation of arenes and heterocycles in hexafluoroisopropanol. J Org Chem 83:930-938. https://doi.org/10.1021/acs.joc.7b029 20

22. Pramanick PK, Hou Z-L, Yao B (2017) Mechanistic study on iodine-catalyzed aromatic bromination of aryl ethers by $\mathrm{N}$-bromosuccinimide. Tetrahedron 73:7105-7114. https://doi. org/10.1016/j.tet.2017.10.073

23. Lima HHLB, da Silva GR, Pena JM, Cella R (2017) Ultrasoundassisted bromination of aromatic rings using $\mathrm{NaBr} / \mathrm{H}_{2} \mathrm{O}_{2}$ system. ChemistrySelect 2:9624-9627. https://doi.org/10.1002/ slct.201702023

24. Salmasi R, Gholizadeh M, Salimi A, Garrison JC (2016) The synthesis of 1,2-ethanediylbis(triphenylphosphonium)ditribromide as a new brominating agent in the presence of solvents and under solvent-free conditions. J Iran Chem Soc 13:2019-2028. https://doi.org/10.1007/s13738-016-0919-6

25. Virgil SC, Jenkins PR, Wilson AJ, Romero MDG (2006) N-Bromosuccinimide. In: Paquette LA, Crich D, Molander G, Van Dyke AR, Jamison TF (eds) Encyclopaedia of reagents for organic synthesis. Wiley, New York. https://doi.org/10.1002/047084289X.rb318 .pub2

26. Saikia E, Bora SJ, Chetia B (2015) $\mathrm{H}_{2} \mathrm{O}_{2}$ in WERSA: an efficient green protocol for ipso-hydroxylation of aryl/heteroarylboronic acid. RSC Adv 5:102723-102726. https://doi.org/10.1039/c5ra2 $1354 a$

27. Surneni N, Baura NC, Saikia B (2016) Application of natural feedstock extract: the Henry reaction. Tetrahedron Lett 57:28142817. https://doi.org/10.1016/j.tetlet.2016.05.048

28. Sarmah M, Mondal M, Bora U (2017) Agro-waste extract based solvents: emergence of novel green solvent for the design of 
sustainable processes in catalysis and organic chemistry. ChemistrySelect 2:5180-5188. https://doi.org/10.1002/slct.201700580

29. Leitemberger A, Böhs LMC, Rosa CH, Da Silva C, Galetto FZ, Godoi M (2019) Synthesis of symmetrical diorganyl disulfides employing WEB as an eco-friendly oxidative system. ChemistrySelect 4:7686-7690. https://doi.org/10.1002/slct.201901385

30. Kumar NS, Bheeram VR, Mukkamala SB, Rao LC, Vasantha R (2018) An efficient and environmentally benign protocol for the 1,6-Michael addition of nitroalkanes to 3-methyl-4-nitro5-styrylisoxazoles in WERSA. ChemistrySelect 3:1915-1918. https://doi.org/10.1002/slct.201702788

31. Bagul SD, Rajput JD, Bandre RS (2017) Synthesis of 3-carboxycoumarins at room temperature in water extract of banana peels. Environ Chem Lett 15:725-731. https://doi.org/10.1007/ s10311-017-0645-z

32. Chia PW, Lim BS, Yong FSJ, Poh S-C, Kan S-Y (2018) An efficient synthesis of bisenols in water extract of waste onion peel ash. Environ Chem Lett 16:1493-1499. https://doi.org/10.1007/s1031 1-018-0764-1

33. Godoi M, Leitemberger A, Böhs LMC, Silveira MV, Rafique J, D'Oca MGM (2019) Rice straw extract, an efficient solvent for regioselective hydrothiolation of alkynes. Environ Chem Lett 17:1441-1446. https://doi.org/10.1007/s10311-019-00882-0
34. Polshettiwar V, Decottignies A, Len C, Fihri A (2010) SusukiMiyaura cross-coupling reactions in aqueous media: green and sustainable syntheses of biaryls. Chemsuschem 3:502-522. https://doi.org/10.1002/cssc.200900221

35. Sheldon RA (2005) Green solvents for sustainable organic synthesis: state of the art. Green Chem 7:267-278. https://doi. org/10.1039/b418069k

36. Sravani B, Raghavendra P, Chandrasekhar Y, Reddy YVM, Sivasubramanian R, Venkateswarlu K, Madhavi G, Sarma LS (2019) Immobilization of platinum-cobalt and platinum-nickel bimetallic nanoparticles on pomegranate peel extract-treated reduced graphene oxide as electrocatalyst for oxygen reduction reaction. Int J Hydrog Energy. https://doi.org/10.1016/j. ijhydene.2019.02.204

37. Dai W, Katzenellenbogen JA (1991) Stereoselective Z- and E-bromo enol lactonization of alkynoic acids. J Org Chem 56:6893-6896. https://doi.org/10.1021/jo00024a035

Publisher's Note Springer Nature remains neutral with regard to jurisdictional claims in published maps and institutional affiliations. 